\title{
Atributos do solo e produtividade do milho cultivado em sucessão a plantas de cobertura de inverno
}

\author{
Soil attributes and yield of corn cultivated in succession to winter cover crops
}

\author{
Cleudson José Michelon ${ }^{1 *}$, Emanuele Junges ${ }^{1}$, Carlos Alberto Casali ${ }^{2}$, João Batista Rossetto \\ Pellegrini $^{3}$, Lethícia Rosa Neto ${ }^{4}$, Zanandra Boff de Oliveira ${ }^{4}$ e Marília Boff de Oliveira ${ }^{4}$
}

${ }^{1}$ Instituto Federal Farroupilha, São Vicente do Sul, RS, Brasil. *Autor para correspondência: cleudson.michelon@iffarroupilha.edu.br. ${ }^{2}$ Universidade Tecnológica Federal do Paraná, Dois Vizinhos, PR, Brasil.

${ }^{3}$ Instituto Federal Farroupilha, Frederico Westphalen, RS, Brasil.

${ }^{4}$ Universidade Federal de Santa Maria, Cachoeira do Sul, RS, Brasil.

\begin{abstract}
RESUMO
O objetivo deste trabalho foi avaliar o efeito de diferentes plantas de cobertura de inverno na fertilidade do solo e produtividade da cultura do milho. O experimento foi conduzido por três safras agrícolas, de 2011 a 2014. Os tratamentos utilizados foram as plantas de coberturas de inverno ervilhaca, aveia preta, tremoço azul, nabo forrageiro, azevém e ervilha forrageira cultivadas isoladamente, além dos consórcios aveia preta com ervilhaca, aveia preta com nabo forrageiro e ervilhaca, aveia preta com nabo forrageiro e uma parcela controle, sem uso de plantas de cobertura (Pousio). O delineamento experimental foi de blocos ao acaso com três repetições. Em três safras agrícolas foram avaliados os atributos químicos e físicos do solo, o rendimento de massa seca da parte aérea das plantas de cobertura e o rendimento de grãos do milho cultivado em sucessão. A ervilha forrageira produziu mais matéria seca na safra 2011/2012, enquanto os consórcios aveia + ervilhaca e aveia + nabo + ervilhaca produziram mais nas safras de 2012/2013 e 2013/2014. O rendimento de grãos de milho foi maior em sucessão a fabáceas e consórcios na safra 2011/2012 e em sucessão a aveia + ervilhaca + nabo e tremoço nas safras 2012/2013 e 2013/2014. O cultivo de plantas de cobertura por três anos consecutivos resultou em incremento nos teores de matéria orgânica e na disponibilidade de fósforo e potássio no solo.
\end{abstract}

PALAVRAS-CHAVE: adubação verde, manejo de solo, rotação de culturas.

\section{ABSTRACT}

The aim of this study was to evaluate the effect of different winter cover plants on soil physical and chemical attributes and corn crop productivity. The experiment was carried out for three crops, from 2011 to 2014. The treatments were winter cover crops vetch, black oat, blue lupin, wild radish, ryegrass and field pea cultivated alone and intercropped with black oat + vetch, black oat + wild radish + vetch, black oat + wild radish, and a control treatment, without the use of cover crops (fallow). The experimental design consisted of random blocks with three repetitions. Chemical and physical soil parameters were evaluated, as well as yield of dry plant biomass of the cover crops and yield of corn cultivated in sucession. The greatest production of dry mass for field pea was obtained in the 2011/2012 crop and for the treatments with black oat + vetch and black oat + wild radish + vetch, in 2012/2013 and 2013/2014. Corn grain yield was higher in the treatments utilizing Fabaceae species and intercropping in the 2011/2012 crop. In the 2012/2013 and 2013/2014 crops, the greatest yield of corn grains was found in the treatments with black oat + vetch + wild radish and blue lupin as cover crops. Growing cover crops for three consecutive years resulted in increase in the organic matter contents and availability of phosphorus and potassium in the soil.

KEYWORDS: green manure, soil management, crop rotation.

\section{INTRODUÇÃO}

A atividade agrícola tem o desafio de manter a produtividade de forma sustentável (PLAZA-BONILLA et al. 2016), principalmente em regiões tropicais e subtropicais, como no Brasil, onde, em geral, os processos erosivos e as taxas de decomposição da matéria orgânica do solo (MOS) são maiores que regiões temperadas, o que torna fundamental a implementação de práticas de manejo conservacionista dos 
solos.

Nesse contexto, o Sistema Plantio Direto (SPD) revolucionou o manejo do solo e da água em áreas agrícolas brasileiras, pois essa técnica prevê a mobilização do solo apenas na linha de semeadura associada a manutenção dos resíduos culturais na sua superfície e rotação de culturas. DOMIT et al. (2014) verificaram que o tempo de adoção do SPD influenciou positivamente nos atributos do solo, diminuindo a resistência mecânica à penetração e a densidade do solo com 15 e 11 anos de adoção. Em conjunto, em 30 anos de uso o SPD aumentou os teores de vários nutrientes e da MOS, especialmente na camada superficial, intensificando-se com o tempo de adoção, inclusive, mantendo os teores de cálcio (Ca), magnésio $(\mathrm{Mg})$, saturação por bases $(\mathrm{V} \%)$ e acidez do solo de camadas subsuperficiais similares aos encontrados em sistemas com revolvimento do solo (DEBIASI et al. 2013).

O sucesso do SPD fez com que atualmente predominasse no cultivo de cereais e oleaginosas no Brasil, tendo na safra agrícola 2013/14, 32 milhões de hectares sob esse sistema (FEBRAPDP 2014), o que representa $56 \%$ dos 57 milhões de ha cultivados com cereais e grãos (IBGE 2014). Porém, devido ao seu manejo inadequado, os solos sob SPD enfrentam problemas relacionados à compactação, ao uso excessivo de fertilizantes, a erosão e a consequente contaminação dos recursos hídricos superficiais.

Um exemplo é a utilização de áreas de pousio em sucessão as culturas comerciais, que pode não trazer ao agricultor os benefícios advindos do SPD, além de dificultar o manejo de plantas daninhas nas culturas comerciais, pelo aumento do seu banco de sementes (BORGES et al. 2015). Uma das premissas do SPD é manter o solo sempre coberto por plantas em desenvolvimento e por resíduos vegetais. Essa cobertura tem por finalidade proteger o solo do impacto direto das gotas de chuva, do escorrimento superficial e das erosões hídrica e eólica (REBELLO \& TURETTA 2017).

Para tanto, estimula-se no SPD o cultivo de plantas de cobertura como alternativa para diminuir os problemas relacionados à compactação do solo (REEVES 1994, ALVAREZ et al. 2017). Além disso, as plantas de cobertura absorvem nutrientes e os liberam novamente para o solo quando decompostas, contribuindo também com acréscimo de material orgânico do solo possibilitando aumento na produtividade das próximas culturas (FAGERIA et al. 2005, CARVALHO et al. 2007, FORTE et al. 2018).

Cada espécie de planta de cobertura possui dinâmica específica nos níveis de decomposição e liberação de nutrientes dos seus resíduos. Esse comportamento está relacionado à sua composição, o qual é associado à relação carbono/nitrogênio $(\mathrm{CN})$ e presença de compostos mais lábeis ou recalcitrantes. De acordo com HADAS et al. (2004), esses resíduos são constituídos pelos mesmos grupos de componentes, porém, em diferentes proporções, onde a concentração de nitrogênio $(N)$ desempenha um importante papel nos processos de decomposição e disponibilidade de nutrientes (REDIN et al. 2014).

Algumas espécies da família Fabaceae, além de ciclar o $\mathrm{N}$ disponível no solo, podem utilizar $\mathrm{N}_{2}$ atmosférico por meio da associação com bactérias fixadoras desse elemento. Assim, podem contribuir para atender a demanda de $\mathrm{N}$ de culturas de alta exigência, como o milho, ao serem incluídas em sucessão a essa cultura. Isso reduz o uso excessivo de fertilizantes nitrogenados, os quais potencializam as perdas por lixiviação para águas subterrâneas ou emissões para atmosfera $\left(\mathrm{N}_{2} \mathrm{O}\right)$ (BOUWMAN et al. 2013) ocasionando danos irreparáveis aos recursos ambientais.

As plantas de cobertura podem ser cultivadas isoladamente ou em consórcio com duas, três ou mais espécies, principalmente plantas das famílias Poaceae e Fabaceae. O uso de consórcio de espécies é altamente benéfico pois, além de contribuir para melhorar as propriedades físicas do solo (agregação e estruturação) (ALVAREZ et al. 2017), produz resíduos intermediários quanto a relação CN que favorecem a mineralização de $\mathrm{N}$ e promovem maior equilíbrio e acúmulo de carbono no perfil do solo ao longo do tempo (DONEDA et al. 2012, ZIECH et al. 2015).

No entanto, o desempenho das diferentes plantas de cobertura e seus consórcios em rotação a culturas comerciais, como o milho, varia em função das condições edafoclimáticas de cada Região (CALEGARI 2008). No Sul do Brasil, a inserção de plantas de cobertura de verão é dificultada pela competição por área cultivada com as principais culturas comerciais, como soja, milho e feijão, tornando as plantas de cobertura de inverno uma alternativa mais viável. Para tanto, torna-se necessária a avaliação do desempenho dessas plantas e seus consórcios, a fim de indicar as mais adequadas para anteceder os cultivos de verão.

Nesse aspecto, destaca-se a região Central do Rio Grande do Sul, onde nos últimos 15 anos intensificou-se o cultivo de culturas anuais, principalmente sobre áreas com campo nativo, sendo o município de Tupanciretã o maior produtor de soja do RS, com 146.500 ha cultivados na safra 2016/17 (IBGE 2014). Contudo, nessa Região o cultivo de milho está suprimido, sendo que esse mesmo município cultivou na safra 2016/17 apenas 3.850 ha do cereal, números pouco expressivos em função, 
principalmente, do elevado custo do seu cultivo aliado a suscetibilidade dessa Região a estiagem e consequente frustração de safra.

Sabe-se da importância da rotação da soja com a cultura do milho, principalmente no que tange a redução de plantas daninhas e ataque de pragas e doenças, bem como a melhoria das condições de solo (CALEGARI 2008, FRANCHINI et al. 2011, DEBIASI et al. 2013). NASCENTE et al. (2014) verificaram que todas as rotações testadas proporcionam rendimento econômico positivo e foram economicamente viáveis, dando destaque para as rotações entre Poaceae e Fabaceae, fazendo com que o SPD obtivesse maior rentabilidade econômica com a utilização da rotação.

Portanto, a avaliação das plantas de cobertura de inverno mais adaptadas a essa região possibilitaria o cultivo de milho com menor custo, à medida que poderia reduzir a adubação, principalmente a nitrogenada, beneficiando também a cultura da soja em rotação. Neste sentido, o objetivo deste trabalho foi avaliar o efeito das plantas de cobertura de inverno, isoladamente ou em consórcio, sobre as propriedades físicas e químicas do solo e na produtividade de grãos de milho na Região Central do Rio Grande do Sul.

\section{MATERIAL E MÉTODOS}

O estudo foi conduzido na área experimental do Instituto Federal Farroupilha Campus Júlio de Castilhos (latitude de 2913'37 "Sul, longitude de 5340'54" Oeste), com altitude média de 513 metros. O clima é subtropical com temperaturas médias de $21^{\circ} \mathrm{C}$, sendo as temperaturas baixas entre $0{ }^{\circ} \mathrm{C}$ e $10 \stackrel{\circ}{\circ} \mathrm{C}$ no inverno e as temperaturas elevadas entre $20{ }^{\circ} \mathrm{C}$ e $35^{\circ} \mathrm{C}$ no verão. O solo é Argissolo Vermelho distrófico típico e a vegetação original era campo nativo que foi incorporado ao cultivo agrícola nos anos 1980 , sendo cultivado desde os anos 2000 sob SPD.

Em abril de 2010 o solo foi amostrado na camada de 0-0,10 m para caracterização química (Tabela 1). Posteriormente, foi aplicado $3,0 \mathrm{t} \mathrm{ha}^{-1}$ de calcário calcítico para elevar o $\mathrm{pH}$ a 6,0 , o qual foi incorporado com grade niveladora.

Os tratamentos foram implantados no mês de maio dos anos de 2010, 2011, 2012 e 2013 e consistiram em plantas de cobertura de inverno cultivadas isoladamente ou em consórcio, conforme segue: aveia preta + ervilhaca (AP+ER); ervilhaca (Vicia sativa) (ER); aveia preta + nabo forrageiro + ervilhaca $(\mathrm{AP}+\mathrm{NF}+\mathrm{ER})$; tremoço azul (Lupinus angustifolium) (TA); aveia preta (Avena strigosa) (AP); nabo forrageiro (Raphanus sativus L.) (NF); aveia preta + nabo forrageiro ( $\mathrm{AP}+\mathrm{NF}$ ); azevém (Lolium multiflorum) (AZ); ervilha forrageira (Pisum sativum L.) (EF), além de um tratamento controle, com crescimento de plantas voluntárias, denominado pousio (PO). O delineamento experimental foi de blocos ao acaso com três repetições, totalizando 30 parcelas de $48 \mathrm{~m}^{2}$.

$\mathrm{Em}$ todos os anos as plantas de cobertura foram semeadas manualmente em fileiras espaçadas a $0,17 \mathrm{~m}$ e sem aplicação de fertilizante. A densidade de semeadura dos tratamentos isolados de aveia preta, ervilhaca, nabo forrageiro, ervilha forrageira, azevém e tremoço azul foi de 80,60, 15, 60, 50 e $90 \mathrm{~kg} \mathrm{ha}^{-1}$, respectivamente. Nos consórcios foram utilizadas as proporções: aveia $(30 \%)+$ ervilhaca $(70 \%)$; aveia $(30 \%)+$ nabo $(70 \%)$ e aveia $(50 \%)+$ nabo $(50 \%)+$ ervilhaca $(50 \%)$. A porcentagem de sementes utilizadas nos consórcios foi baseada nas densidades utilizadas para cada cultura isoladamente.

Nos anos de 2011, 2012 e 2013, quando as plantas de cobertura estavam em floração plena, coletouse a massa fresca da parte aérea de $2 \mathrm{~m}^{2}$ das parcelas e realizou-se a secagem em estufa de ventilação forçada a $65{ }^{\circ} \mathrm{C}$ para avaliação da massa seca da parte aérea (MSPA). Posteriormente, as plantas de cobertura foram imediatamente dessecadas com herbicida glifosato para a implantação da cultura de milho.

O milho foi cultivado nas safras 2010/2011, 2011/2012, 2012/2013 e 2013/2014 por meio de semeadora com espaçamento de $0,45 \mathrm{~m}$ entre fileiras e população aproximada de 75 mil plantas ha ${ }^{-1}$, sendo utilizadas as cultivares híbridos, Agroeste 1555, Pioneer ${ }^{\circledR} 32 \mathrm{R} 21$, Pioneer ${ }^{\circledR} 30 \mathrm{~F} 53$, respectivamente, todos eles com a tecnologia Bt. Nas duas primeiras safras, a adubação de base foi feita com superfosfato triplo e cloreto de potássio aplicados no sulco de semeadura em doses de $55 \mathrm{~kg} \mathrm{ha}^{-1}$ de $\mathrm{P}_{2} \mathrm{O}_{5}$ e $\mathrm{K}_{2} \mathrm{O}$, respectivamente. Nas safras 2012/2013 e 2013/2014, seguiu-se a recomendação da CQFS- RS/SC (2004), visando a produtividade de $10,0 \mathrm{Mg} \mathrm{ha}^{-1}$, que equivaleu às doses de 215 e $175 \mathrm{~kg} \mathrm{ha}^{-1}$ de $\mathrm{P}_{2} \mathrm{O}_{5}$ e 130 e 110 $\mathrm{kg} \mathrm{ha}^{-1}$ de $\mathrm{K}_{2} \mathrm{O}$, respectivamente. A dose máxima de $\mathrm{K}_{2} \mathrm{O}$ adicionada no sulco de semeadura foi $80 \mathrm{~kg} \mathrm{ha}^{-1} \mathrm{e}$ o restante adicionado em cobertura logo após a semeadura. $O$ fertilizante nitrogenado não foi utilizado, a fim de avaliar a contribuição das plantas de cobertura com o referido nutriente.

Os tratamentos fitossanitários foram realizados de acordo com recomendações técnicas para culturas de milho. Além da dessecação das plantas de cobertura, foi utilizado herbicida para o controle de plantas daninhas, bem como inseticida para controle de insetos.

Em função de uma severa estiagem na safra 2010/2011, não foram avaliados a produtividade de 
milho e os atributos químicos do solo. Nas demais safras, o rendimento de grãos de milho foi quantificado com a colheita de espigas em $2 \mathrm{~m}$ lineares de plantas em cada parcela. Em seguida, as espigas foram debulhadas e determinou-se a massa dos grãos e seu teor de umidade.

Após a colheita do milho, o solo foi amostrado com pá de corte nas camadas 0,00-0,05 m e 0,05-0,10 m, em 2011/2012 e 2012/2013, e 0,00-0,10 m em 2013/2014. O solo foi seco, moído e peneirado em malha 2,0 mm para determinação do $\mathrm{pH}-\mathrm{H}_{2} \mathrm{O}$, acidez potencial $(\mathrm{H}+\mathrm{Al})$, teor de $\mathrm{Ca}$ e $\mathrm{Mg}$ trocáveis, $\mathrm{P}$ e $\mathrm{K}$ disponíveis (Mehlich 1), conforme métodos descritos em TEDESCO et al. (1995), e o teor de carbono orgânico do solo por combustão úmida, conforme EMBRAPA (1997), para posteriormente estimar a matéria orgânica (MO).

Após a colheita do milho da safra 2013/2014, foram determinados os atributos físicos do solo, densidade do solo (Ds), macroporosidade (Ma), microporosidade (Mi) e porosidade total (Pt). Para essas determinações, coletaram-se amostras de solo indeformadas, com auxílio de um cilindro de metal com dimensões de $0,056 \mathrm{~m}$ de diâmetro e $0,03 \mathrm{~m}$ de altura e $0,074 \mathrm{dm}^{-3}$ de volume, na camada $0,00-0,05 \mathrm{~m}$ para manter a estrutura do solo. A Ds foi determinada pelo método do anel volumétrico, a Mi pelo método da mesa de sucção (EMBRAPA 1997), a Pt com base na percentagem de umidade de saturação no solo e Ma a pela diferença entre Pt e Mi.

Os dados foram analisados utilizando o programa Sisvar para análise de variância e, quando significativos, as médias foram comparadas pelo teste de Scott-Knott a 5\% de probabilidade de erro.

\section{RESULTADOS E DISCUSSÃO}

Na safra 2011/2012, a produção de MSPA das plantas de cobertura foi menor (Figura 1A) em relação as demais safras, devido à baixa disponibilidade de $\mathrm{P}$ e $\mathrm{K}$ do solo e à ausência de adubação na implantação dos cultivos. Nesse ano, a ervilha forrageira obteve o maior rendimento, enquanto os tratamentos com azevém, nabo forrageiro e tremoço o menor rendimento de MSPA. Isso indica que a ervilha forrageira é uma espécie mais adaptada a solos com menor disponibilidade de nutriente.

Nas safras 2012/2013 (Figura 1B) e 2013/2014 (Figura 1C), a maior produtividade de MSPA se deu nos consórcios aveia + nabo + ervilhaca e aveia + ervilhaca, enquanto as menores foram com as Poaceae azevém e aveia preta em cultivos solteiros, corroborando os dados encontrados por GIACOMINI et al. (2003a) e DONEDA et al. (2012). Já ZIECH et al. (2015) avaliaram plantas de cobertura de inverno antecedendo a cultura de milho e obtiveram o maior rendimento de MSPA nos cultivos com aveia preta consórcios aveia + ervilhaca e aveia + nabo + ervilhaca.

Os consórcios que incluíram a ervilhaca proporcionaram a maior produtividade de MSPA das plantas de cobertura de inverno acumulada nas três safras, sendo os únicos a superar $10.000 \mathrm{~kg} \mathrm{ha}^{-1}$ (Figura 1D). Ao mesmo tempo, o azevém e a aveia preta cultivados solteiros, que são as principais culturas utilizadas no período de inverno na Região Central do RS (IBGE 2014), acumularam a menor quantidade de MSPA, sendo que o azevém acumulou apenas $4.000 \mathrm{~kg} \mathrm{ha}^{-1}$. CARVALHO et al. (2007) também encontraram que os consórcios que utilizaram ervilhaca obtiveram maior produtividade de MSPA, comparativamente as culturas isoladas de azevém, nabo e ervilhaca. ZIECH et al. (2015) afirmam que o uso de consórcios permite incorporar, ao sistema, os benefícios isolados das culturas que o compõem e que seu uso deve ser estimulado em SPD.

Em um estudo realizado com diferentes plantas de cobertura, NICOLOSO et al. (2008) verificaram que o consórcio com nabo + aveia preta aumentou a produção de fitomassa quando comparado com a aveia isoladamente. Resultados semelhantes foram encontrados por DONEDA et al (2012), que observaram maior MSPA com a inserção do nabo forrageiro em sistema de consórcio com aveia e centeio, atribuído ao rápido crescimento inicial desta espécie em relação às espécies de Poaceae.

Na safra 2011/2012 (Figura 2A), a produtividade média de milho cultivado após as diferentes culturas de cobertura foi menor quando comparada à obtida na safra 2012/2013 (Figura 2B). Isto pode ser explicado pela baixa produção de MSPA das plantas de cobertura na safra 2011/2012 (Figura 1A) que em consequência disso, resultou em menor efeito das culturas de cobertura na adição e reciclagem de nutrientes, refletindo-se em menor disponibilidade de nutrientes, especialmente $\mathrm{N}$, para a cultura de milho. As baixas concentrações de $\mathrm{P}$ e $\mathrm{K}$ no solo no início do estudo (Tabela 1) também podem ter contribuído para esses resultados. TONITTO et al. (2006), observaram que em solo com baixa disponibilidade de P e K, o uso de culturas de cobertura, principalmente as leguminosas, não afetam o rendimento do milho. 


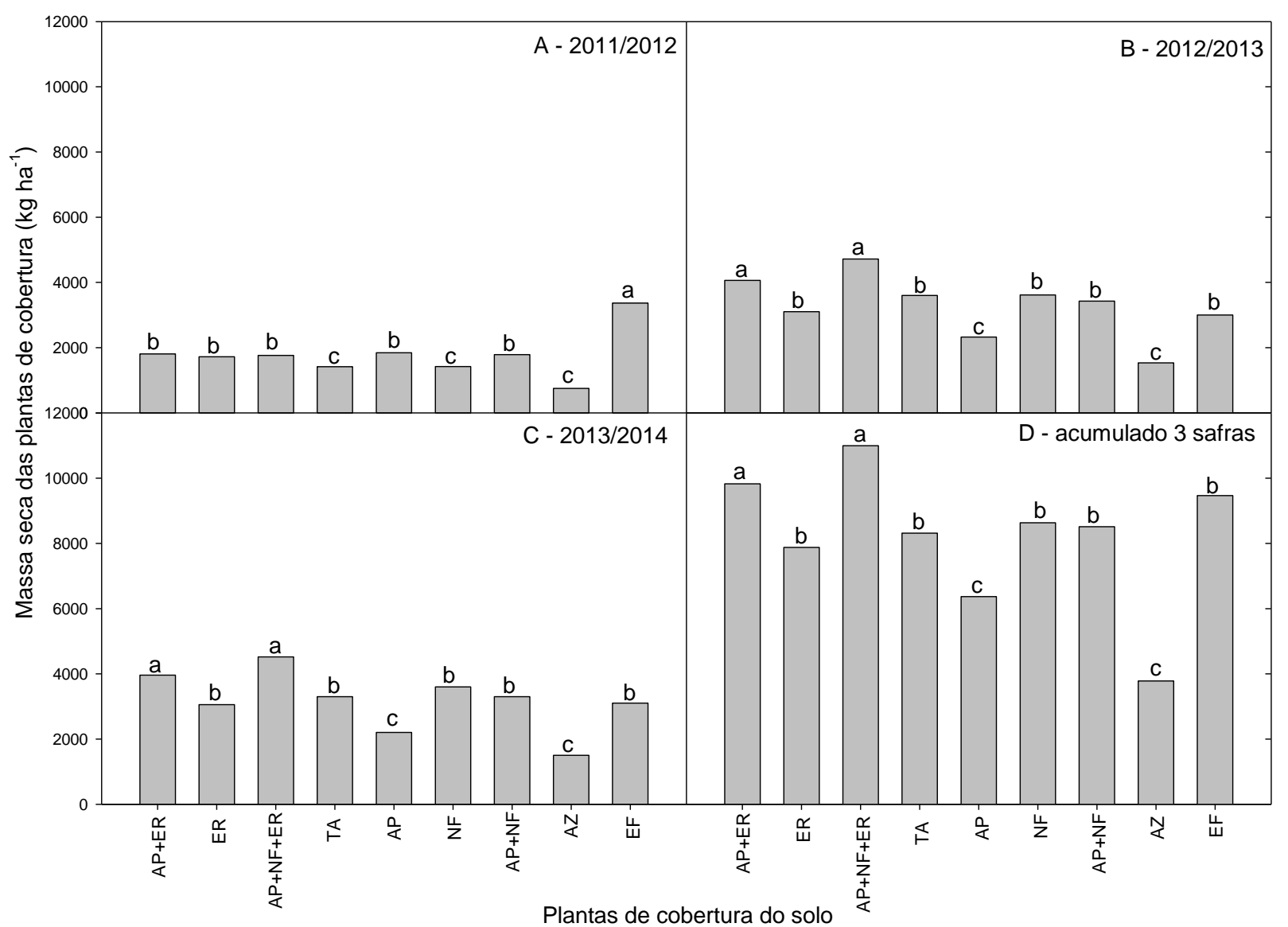

Figura 1. Massa seca da parte aérea de plantas de cobertura nas safras 2011/2012 (A), 2012/2013 (B), 2013/2014 (C) e acumulada (D) em função de diferentes tratamentos com plantas de cobertura do solo. Júlio de Castilhos, 2018. Onde: $A P+E R$ = aveia preta + ervilhaca; $E R$ = ervilhaca; $A P+N F+E R$ = aveia preta + nabo forrageiro + ervilhaca; $\mathrm{TA}=$ tremoço azul; $\mathrm{PO}=$ pousio; $\mathrm{AP}=$ aveia preta; $\mathrm{NF}=$ nabo forrageiro; $\mathrm{AP}+\mathrm{NF}$ = aveia preta + nabo forrageiro; $\mathrm{AZ}=$ azevém; $\mathrm{EF}=$ ervilha forrageira. Colunas contendo mesmas letras não diferem pelo teste de Scott-Knott a $5 \%$.

Figure 1. Dry mass of cover crops in the 2011/2012 (A), 2012/2013 (B), 2013/2014 (C) crops, and accumulated $(D)$ due to different treatments with cover crops. Júlio de Castilhos, 2018. In which: $A P+E R=$ black oat + vetch; $E R=$ vetch $A P+N F+E R=$ black oat + wild radish + vetch $; A=$ blue lupin; $P O=$ fallow; $A P$ = black oat; $N F=$ wild radish; $A P+N F=$ black oat + wild radish; $A Z=$ ryegrass; $E F=$ field pea. Columns with the same letters did not differ by Scott - Knott test at $5 \%$.

Nas safras 2012/2013 (Figura 2B) e 2013/2014 (Figura 2C), os tratamentos com cultivo isolado ou em consórcio de espécies Fabaceae apresentaram os maiores rendimentos de grãos de milho, comparativamente ao cultivo isolado das espécies Poaceae e Brassicaseae, destacando o consórcio aveia + ervilhaca + nabo e o cultivo isolado de tremoço, com valores atingindo $9.000 \mathrm{~kg} \mathrm{ha}^{-1}$ na safra 2012/2013 (Figura 2B). Estes resultados corroboram com os encontrados por ALVAREZ et al. (2017), que obtiveram maior rendimento de milho quando utilizada a ervilhaca como planta de cobertura. MIGUEZ e BOLLERO (2005) avaliando resultados de 37 experimentos conduzidos nos Estados Unidos e no Canadá constataram que o cultivo de plantas de cobertura da família Fabaceae e consórcios aumentaram de 21 a $24 \%$ a produção de milho, respectivamente, enquanto o cultivo solteiro de espécies de Poaceae não influenciaram no rendimento.

Na safra 2013/2014 (Figura 2C) os rendimentos de grãos foram menores em relação a 2012/2013 (Figura 2B), devido a um período de déficit hídrico no início do estádio reprodutivo na cultura de milho. $\mathrm{O}$ déficit hídrico durante o estádio reprodutivo não garante a recuperação da capacidade produtiva da cultura, uma vez que os eventos reprodutivos são mais rápidos do que os verificados durante o período vegetativo (BERGAMASCHI et al. 2006). Nesse estádio fenológico, a cultura do milho se torna extremamente sensível a períodos de estiagem, devido a processos fisiológicos ligados a formação do zigoto e início do enchimento de grãos (SCHUSSLER \& WESTGATE 1991). 


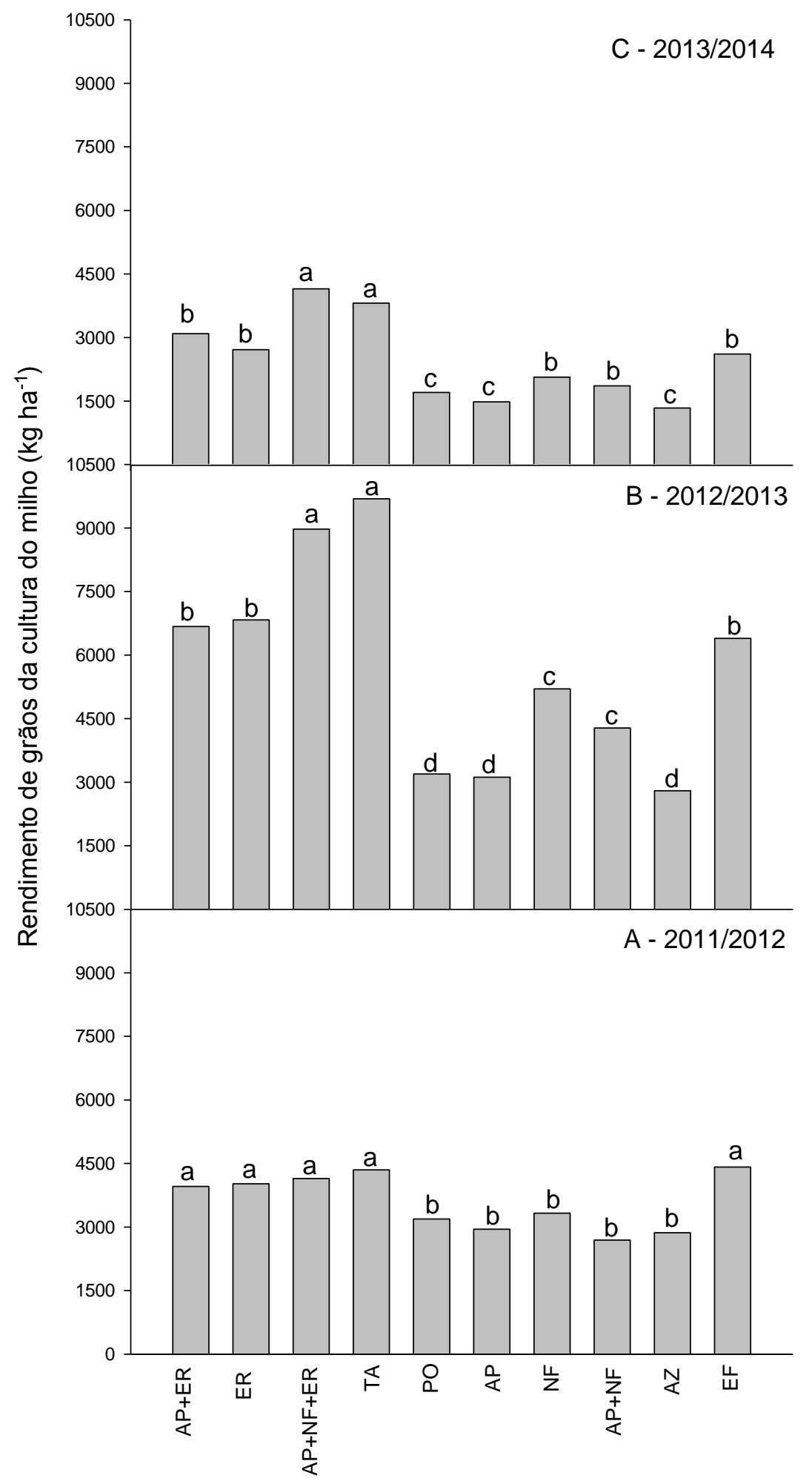

Plantas de cobertura do solo

Figura 2. Rendimento de grãos de milho nas safras 2011/2012 (A), 2012/2013 (B), 2013/2014 (C), em função de diferentes tratamentos com plantas de cobertura do solo. Júlio de Castilhos, 2018. Onde: $\mathrm{AP}+\mathrm{ER}=$ aveia preta + ervilhaca; $\mathrm{ER}=$ ervilhaca; $\mathrm{AP}+\mathrm{NF}+\mathrm{ER}=$ aveia preta + nabo forrageiro + ervilhaca; $\mathrm{TA}=$ tremoço azul; $\mathrm{PO}=$ pousio; $\mathrm{AP}=$ aveia preta; $\mathrm{NF}$ = nabo forrageiro; $\mathrm{AP}+\mathrm{NF}=$ aveia preta + nabo forrageiro; $\mathrm{AZ}=$ azevém; $\mathrm{EF}=$ ervilha forrageira. Colunas contendo mesmas letras não diferem pelo teste de Scott-Knott a $5 \%$.

Figure 2. Corn grain yield in the 2011/2012 (A), 2012/2013 (B), 2013/2014 (C) crops, due to different treatments with cover crops. Júlio de Castilhos, 2018. In which: $A P+E R=$ black oat + vetch; $E R=$ vetch; $A P+N F+E R$ = black oat + wild radish + vetch; $T A=$ blue lupin; $P O=$ fallow; $A P=$ black oat; $N F=$ wild radish; $A P+N F=$ black oat + wild radish; $A Z=$ ryegrass; $E F=$ field pea. Columns with the same letters did not differ by Scott - Knott test at $5 \%$. 
Efeitos positivos no rendimento da cultura do milho em sucessão a espécies da família Fabaceae também foram observados em outros estudos. GIACOMINI et al. (2004), verificaram em três safras consecutivas rendimento $40 \%$ maior de grãos do milho quando em sucessão a espécies da família Fabaceae, do que aquelas da família Poaceae, justificado pelo aumento na disponibilidade de $\mathrm{N}$ no solo e consequente maior acúmulo de $\mathrm{N}$ na cultura do milho. SILVA et al. (2006a), encontraram massa de mil grãos e rendimento de grãos superiores onde a semeadura de milho sucedeu o cultivo de crotalária, quando comparado com a cobertura de milheto ou vegetação espontânea (pousio). PLAZA-BONILLA et al. (2016), também verificaram efeitos positivos da utilização de ervilha de inverno antecedendo a cultura do trigo devido a maior concentração de $\mathrm{N}$ disponibilizado por aquela cultura. FORTE et al. (2018), observaram, por três safras consecutivas, que o rendimento de grãos de milho após ervilhaca e aveia + ervilhaca, foi superior àquele obtido após pousio e aveia. De acordo com COOMBS et al. (2017), os cultivos de espécies da família Fabaceae em geral proporcionam maiores rendimentos de milho pelo fato de promoverem maior disponibilidade de $\mathrm{N}$.

Nas safras 2011/2012 e 2012/2013 o cultivo das plantas de cobertura de inverno não interferiram nos atributos químicos do solo. Esse resultado pode ser atribuído ao pouco tempo de cultivo que não foi suficiente para afetar tais variáveis. CUNHA et al. (2011) também não observaram efeitos das plantas de cobertura sobre as propriedades químicas do solo avaliadas nos primeiros $0,20 \mathrm{~m}$ após quatro safras, sob manejo convencional ou plantio direto.

$\mathrm{Na}$ safra 2013/2014 também não houve efeito das plantas de cobertura de inverno sobre $\mathrm{pH}-\mathrm{H}_{2} \mathrm{O}$, $\mathrm{H}+\mathrm{Al}$ e teores de $\mathrm{Ca}$ e $\mathrm{Mg}$ trocáveis (Tabela 1). O comportamento de $\mathrm{Ca}$ e $\mathrm{Mg}$ nos solos é variável devido a fatores ambientais, classe de solo, sequência de culturas, adubação e mobilidade de cada elemento no solo (ALMEIDA et al. 2005). Além disso, como a acidez do solo foi corrigida antes da implantação do experimento, os teores desses atributos são altos, logo, menos sensíveis a diferentes práticas de manejo.

Tabela 1. Atributos químicos do solo da camada $0-10 \mathrm{~cm}$ em função das diferentes plantas de cobertura do inverno. Júlio de Castilhos, 2018.

Table 1. Soil chemical atributes of the layer $0-10 \mathrm{~cm}$ depending on the different winter cover crops. Júlio de Castilhos, 2018.

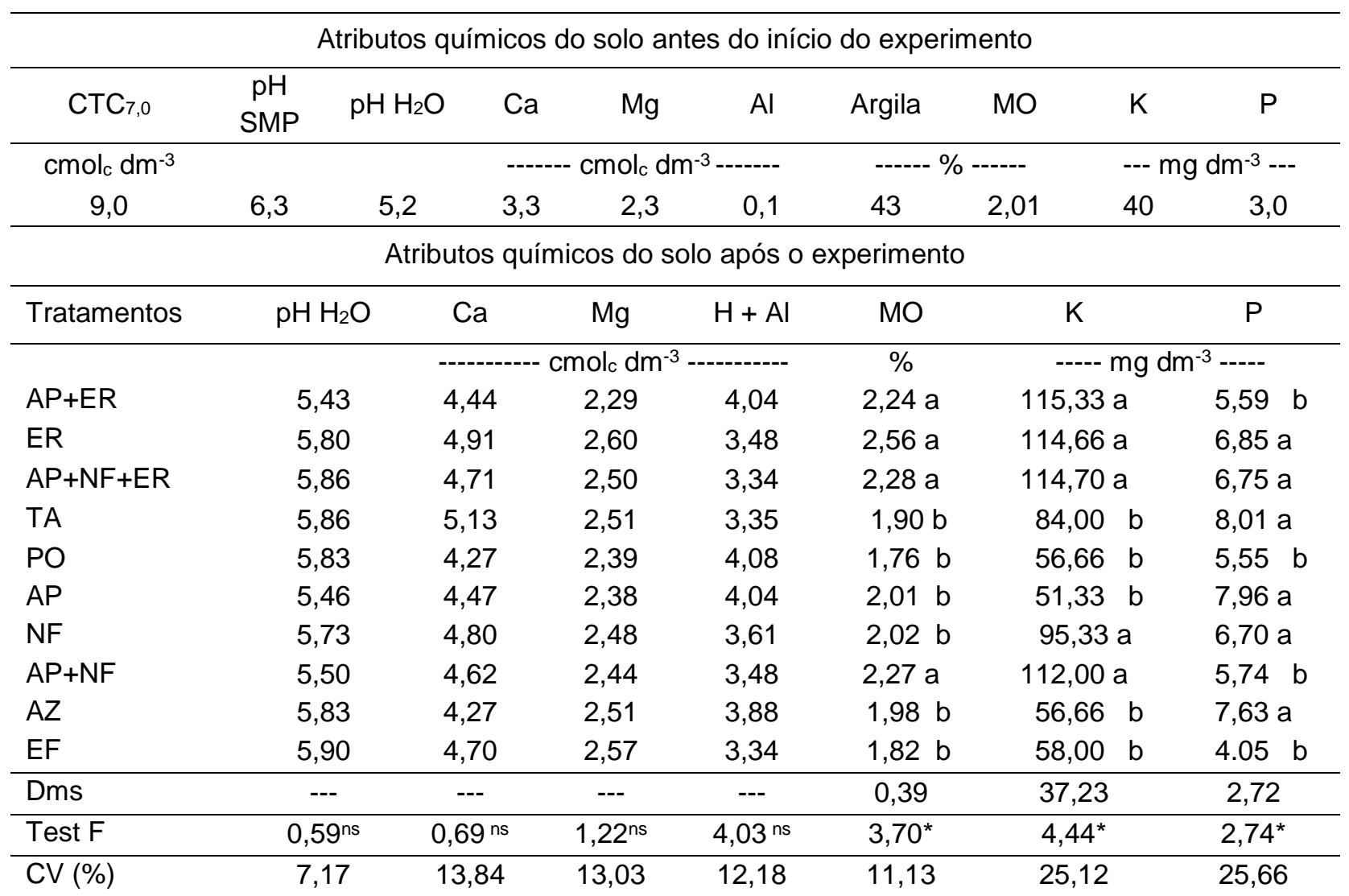

Onde: $\mathrm{AP}+\mathrm{ER}$ = aveia preta + ervilhaca; $\mathrm{ER}=$ ervilhaca; $\mathrm{AP}+\mathrm{NF}+\mathrm{ER}$ = aveia preta + nabo forrageiro + ervilhaca; $\mathrm{TA}=$ tremoço azul; $\mathrm{PO}=$ pousio; $\mathrm{AP}=$ aveia preta; $\mathrm{NF}=$ nabo forrageiro; $\mathrm{AP}+\mathrm{NF}=$ aveia preta + nabo forrageiro; $\mathrm{AZ}=$ azevém; $E F$ = ervilha forrageira. Os valores seguidos de mesmas letras na coluna não diferem pelo teste de Scott-Knott a $5 \%$. Significado: * = significativo $(p<0,05)$; ns= não significativo. 
Entretanto, nessa mesma safra, as plantas de cobertura influenciaram no teor de matéria orgânica (MO) e na disponibilidade de $\mathrm{K}$ e $\mathrm{P}$ (Tabela 1). Os maiores teores de $\mathrm{MO}$ foram promovidos pelos consórcios aveia + nabo + ervilhaca, aveia + ervilhaca, aveia + nabo e pela ervilhaca cultivada isoladamente. Os consórcios foram os tratamentos com maior acúmulo de MSPA (Figura 1D), o que pode ter contribuído para esse aumento da $\mathrm{MO}$ do solo. O consórcio de diferentes plantas de cobertura aumenta a possibilidade do manejo do solo ser bem sucedido, pois o uso simultâneo de plantas com diferentes taxas de decomposição, principalmente devido à inclusão de espécies com alto teor de lignina, como a aveia favorece o incremento no teor de MO (CALEGARI 2008). Assim, a associação entre Poaceae e Fabaceae ou Brassicaceae, conforme recomendado por esse autor, aumenta a presença de resíduos na superfície do solo, o que beneficia simultaneamente a ciclagem de nutrientes e a acumulação de MO. Em estudo realizado utilizando ervilhaca solteira como cultura de cobertura em um sistema de rotação, SISTI et al. (2004) também encontraram incremento no teor de MO com o uso dessa cultura e atribuíram esse resultado a grande produção de raízes.

A disponibilidade de $\mathrm{K}$ no solo foi maior nos três consórcios avaliados, sendo que dois deles apresentaram o maior acúmulo de MSPA, e nos cultivos isolados de ervilhaca e nabo forrageiro (Tabela 1). GIACOMINI et al. (2003a) observaram que os tratamentos com maior ciclagem de $\mathrm{K}$ foram os constituídos por consórcios e o nabo cultivado isoladamente, os quais não diferiram entre si. Além disso, o maior acúmulo de MSPA contribui para maior ciclagem do $\mathrm{K}$ e consequente aumento da sua disponibilidade no solo.

Contudo, além da produção de MSPA, a concentração do nutriente no tecido vegetal e a taxa de liberação do nutriente do tecido são fatores que interferem na ciclagem do $\mathrm{K}$ e dimensiona a capacidade da espécie em absorver o nutriente. GIACOMINI et al. (2003b) verificaram que a ervilhaca comum e o nabo forrageiro cultivados isoladamente foram as espécies com maior concentração de $\mathrm{K}$ no tecido vegetal e maior velocidade de sua liberação do resíduo cultural, pois aos 15 dias do manejo das culturas apenas cerca de $10 \%$ e $15 \%$ do $\mathrm{K}$ permanecia nos resíduos culturais dessas espécies, respectivamente, enquanto na aveia $45 \%$ do $\mathrm{K}$ ainda persistia no resíduo. Assim, no presente estudo isso pode explicar o aumento na disponibilidade de $\mathrm{K}$ no solo sob os cultivos isolados de ervilhaca e nabo forrageiro, mesmo que não tenham apresentado as maiores produtividades de MSPA.

A maior disponibilidade de $P$ foi encontrada no solo com as culturas de tremoço, ervilhaca, nabo, azevém, aveia e aveia + nabo + ervilhaca (Tabela 1). GIACOMINI et al. (2003a) verificaram que a ervilhaca e o nabo forrageiro foram as culturas com maior capacidade de acúmulo de $\mathrm{P}$ no tecido vegetal, o que pode explicar a maior ciclagem de $\mathrm{P}$ no solo e o aumento da disponibilidade onde cultivou-se essas espécies isoladamente ou em consórcio. De acordo com RHEINHEIMER et al. (1998), a disponibilidade de P no solo se dá devido ao efeito das plantas de cobertura em proporcionar maior acúmulo de $\mathrm{MO}$, favorecendo a liberação de compostos orgânicos que competem com o $\mathrm{P}$ nos sítios de adsorção do solo. $\mathrm{O}$ aumento de MO no solo também favorece a disponibilidade de $P$ na solução do solo (ALMEIDA et al. 2005) devido ao maior retorno pela mineralização do $P$ acumulado na fitomassa (CANELLAS et al. 2003) e maior complexação dos íons Al e Fe por compostos orgânicos na solução de solo, o que diminui a chance de precipitação do $P$ com esses elementos (GUPPY et al. 2005). Já a maior disponibilidade de $P$ no solo cultivado com azevém e aveia pode estar relacionado a menor exportação do nutriente pelo milho, tendo em vista que foram os tratamentos que obtiveram a menor produtividade de grãos (Figura 2).

Assim, das plantas de cobertura avaliadas, os tratamentos com ervilhaca e aveia + nabo + ervilhaca foram os únicos que aumentaram simultaneamente os teores de $\mathrm{MO}$ e de $\mathrm{K}$ e $\mathrm{P}$ disponíveis. Esse resultado é importante para o Planalto Médio do Estado do RS, região do estudo, onde somente cultivos solteiros de aveia e azevém são tradicionalmente realizados, com pouca atenção dada ao uso de espécies de Fabaceae, que podem ser utilizadas em consórcio com aquelas culturas ou solteiras.

Não houve efeito das plantas de cobertura de inverno nos atributos físicos do solo avaliados. Os valores médios de $\mathrm{Ds}$, Mi, Ma e Pt foram de 1,46 $\mathrm{Mg} \mathrm{m}^{-3}, 0,33,0,17$ e 0,50 $\mathrm{m}^{3} \mathrm{~m}^{-3}$, respectivamente. MICHELON (2007) estabeleceu valores críticos de Ds e Ma, de acordo com o teor de argila nos solos, para caracterização da compactação do solo. Considerando esses valores como referência, independentemente do tratamento, o solo da camada avaliada não apresentou compactação.

A ausência de efeito de plantas de cobertura do solo de inverno sobre atributos físicos do solo também foi observada por NICOLOSO et al. (2008), SILVEIRA JUNIOR et al. (2012), CALONEGO et al. (2017). Resultados contrastantes a estes foram obtidos por ALVAREZ et al. (2017) que, em trabalhos com plantas de cobertura do solo de inverno em solos da região do pampa argentino, verificaram que a Ds nos primeiros $0,05 \mathrm{~m}$ do solo foi levemente influenciada pelo uso de plantas de cobertura, em relação ao pousio. 
Essa redução na Ds foi atribuída pelo alto incremento no teor de $\mathrm{MO}$ nos tratamentos com plantas de cobertura do solo em relação ao pousio, destacando que foi um estudo de longo prazo. GUARESCHI et al. (2012) observaram menores valores de Ds em área com 20 anos de SPD em comparação a uma área com 3 anos de SPD, evidenciando que as respostas das plantas de cobertura nos atributos físicos do solo ocorrem a longo prazo.

\section{CONCLUSÃO}

Os consórcios das espécies de aveia preta + ervilhaca e aveia preta + ervilhaca + nabo forrageiro produziram as maiores quantidades de massa seca da parte aérea no acumulado das três safras avaliadas.

Na Região Central do Rio Grande do Sul, o cultivo por três safras consecutivas de ervilhaca e do consórcio aveia preta + ervilhaca + nabo forrageiro elevaram o teor de matéria orgânica e a disponibilidade de fósforo e potássio do solo.

Os maiores rendimentos de grãos da cultura do milho foram obtidos com a utilização do consórcio aveia preta + ervilhaca + nabo forrageiro e do tremoço azul utilizado em cultivo isolado.

\section{REFERÊNCIAS}

ALMEIDA JA et al. 2005. Propriedades químicas de um Cambissolo Húmico sob preparo convencional e semeadura direta após seis anos de cultivo. Revista Brasileira de Ciência do Solo 29: 437-445.

ALVAREZ R et al. 2017. Cover crop effects on soils and subsequent crops in the pampas: A meta-analysis. Soil and Tillage Research 170: 53-65.

BERGAMASCHI H et al. 2006. Déficit hídrico e produtividade da cultura do milho. Pesquisa Agropecuária Brasileira 41: 243-249.

BORGES WLB et al. 2015. Plantas de cobertura para o noroeste do estado de São Paulo. Ciência Rural 45: 799-805.

BOUWMAN AF et al. 2013. Global trends and uncertainties in terrestrial denitrification and $\mathrm{N}_{2} \mathrm{O}$ emissions. Philosophical Transactions of the Royal Society B: Biological Sciences 368: 20130112.

CALEGARI A. 2008. Plantas de cobertura e rotação de culturas no sistema de plantio direto. Informações Agronômicas 122: $18-21$.

CALONEGO J et al. 2017. Soil compaction management and soybean yields with cover crops under no-till and ocasional chiseling. European Journal of Agronomy 85: 31-37.

CANELLAS LP et al. 2003. Propriedades químicas de um Cambissolo cultivado com cana-de-açúcar, com preservação do palhiço e adição de vinhaça por longo tempo. Revista Brasileira de Ciência do Solo 27: 935-944.

CARVALHO IQ et al. 2007. Espécies de cobertura de inverno e nitrogênio na cultura do milho em sistema plantio direto. Scientia Agraria 8: 179-184.

CQFS-RS/SC. 2004. Comissão de Química e Fertilidade do Solo RS/SC. Manual de adubação e calagem para solos do RS e SC. 10.ed. Porto Alegre: SBSC. 394p.

COOMBS C et al. 2017. Legume cover crop management on nitrogen dynamics and yield in grain corn systems. Field Crops Research 201: 75-85.

CUNHA EQ et al. 2011. Atributos químicos de solo sob produção orgânica influenciados pelo preparo e por plantas de cobertura. Revista Brasileira de Engenharia Agrícola e Ambiental 15: 1021-1029.

DEBIASI H et al. 2013. Sistemas de preparo do solo: trinta anos de pesquisas na Embrapa Soja. Londrina: Embrapa Soja. Documentos 342. 72p.

DOMIT LA et al. 2014. Tempo de adoção do sistema plantio direto e a relação com atributos do solo. Revista Agrarian 7: 560-569.

DONEDA A et al. 2012. Fitomassa e decomposição de resíduos de plantas de cobertura puras e consorciadas. Revista Brasileira de Ciência do Solo 36: 1714-1723.

EMBRAPA. 1997. Empresa Brasileira de Pesquisa Agropecuária. Manual de Métodos de Análise de Solo. 2.ed. RJ: EMBRAPA-CNPS. 212p.

FAGERIA NK et al. 2005. Role of cover crops in improving soil and row crop productivity. Communications in Soil Science and Plant Analysis 36: 2733-2757.

FEBRAPDP. 2014. Federação Brasileira do Plantio Direto na Palha. Evolução do Sistema Plantio Direto no Paraná. 4p. Disponível em: https://febrapdp.org.br/download/EVOLUCAO_DO_SPD_NO_PARANA_2014.pdf. Acesso em: 02 set. 2018.

FRANCHINI JC et al. 2011. Rotação de culturas: prática que confere maior sustentabilidade à produção agrícola. Piracicaba: Informações Agronômicas. p. 1-13.

FORTE TS et al. 2018. Coberturas vegetais do solo e manejo de cultivo e suas contribuições para as culturas agrícolas. Revista Brasileira de Ciências Agrárias 13: 1-10.

GIACOMINI SJ et al. 2003a. Matéria seca, relação $\mathrm{C} / \mathrm{N}$ e acúmulo de nitrogênio, fósforo e potássio em misturas de plantas de cobertura de solo. Revista Brasileira de Ciência do Solo 27: 325-334.

GIACOMINI SJ et al. 2003b. Liberação de fósforo e potássio durante a decomposição de resíduos culturais em plantio direto. Pesquisa Agropecuária Brasileira 38: 1097-1104.

GIACOMINI SJ et al. 2004. Consorciação de plantas de cobertura antecedendo o milho em plantio direto. II - Nitrogênio 
acumulado pelo milho e produtividade de grãos. Revista Brasileira de Ciência do Solo 28: 751-762.

GUARESCHI RF et al. 2012. Deposição de resíduos vegetais, matéria orgânica leve, estoques de carbono e nitrogênio e fósforo remanescente sob diferentes sistemas de manejo no Cerrado Goiano. Revista Brasileira de Ciência do Solo 36: 909-920.

GUPPY CN et al. 2005. Competitive sorption reactions between phosphorus and organic matter in soil: A review. Australian Journal Soil Research 43: 189-202.

HADAS A et al. 2004. Rates of decomposition of plant residues and available nitrogen in soil, related to residue composition through simulation of carbon and nitrogen turnover. Soil Biology and Biochemestry 36: 255-266.

IBGE. 2014. Instituto Brasileiro de Geografia e Estatística. Área plantada de Cereais, Leguminosas e Oleaginosas Brasil (Hectares). Disponível em: https://www.ibge.gov.br/estatisticas-novoportal/economicas/agricultura-epecuaria/9201-levantamento-sistematico-da-producao-agricola.html?=\&t=series-historicas . Acesso em: 02 set. 2018.

MICHELON CJ et al. 2007. Qualidade física dos solos irrigados no Rio Grande do Sul. Ciência Rural 37: 1308-1315.

MIGUEZ FE \& BOLLERO GA. 2005. Review of corn yield response under winter cover cropping systems using metaanalytic methods. Crop Science 45: 2318-2329.

NASCENTE AS et al. 2014. Viabilidade agroeconômica de rotação de culturas e manejo do solo em áreas irrigadas por aspersão. Revista de Ciências Agrárias 57: 72-79.

NICOLOSO RS et al. 2008. Eficiência da escarificação mecânica e biológica na melhoria dos atributos físicos de um Latossolo muito argiloso e no incremento do rendimento de soja. Revista Brasileira de Ciência do Solo 32: 1735-1742.

PLAZA-BONILLA D et al. 2016. Grain legume - based rotations managed under conventional tillage need cover crops to mitigate soil organic matter losses. Soil and Tillage Research 156: 33-43.

REBELLO C \& TURETTA APD. 2017. Ferramentas para avaliação do potencial à prestação de serviços ambientais pelo Sistema plantio direto. Rio de Janeiro: EMBRAPA. 6p. (Comunicado técnico).

REDIN M et al. 2014. How the chemical composition and heterogeneity of crop residue mixture decomposing at the soil surface affects $\mathrm{C}$ and $\mathrm{N}$ mineralization. Soil Biology and Biochemistry 78: 65-75.

REEVES DW. 1994. Cover crops and rotations. In: HATFIELD JL \& STEWARD BA (Eds.). Crops Residue Management. Advances in Soil Science. Boca Raton: Lewis Publisher. p. 125-172.

RHEINHEIMER DS et al. 1998. Modificações em atributos químicos de solo arenoso sob sistema de plantio direto. Revista Brasileira de Ciência do Solo 22: 713-723.

SILVA EC da et al. 2006. Manejo de nitrogênio no milho sob plantio direto com diferentes plantas de cobertura, em Latossolo Vermelho. Pesquisa Agropecuária Brasileira 41: 477-486.

SILVEIRA JUNIOR SD et al. 2012. Qualidade física de um latossolo vermelho sob plantio direto submetido a descompactação mecânica e biológica. Revista Brasileira de Ciência do Solo 36: 1854-1867.

SISTI CPJ et al. 2004. Change in carbon and nitrogen stocks in soil under 13 years of conventional or zero tillage in southern Brazil. Soil and Tillage Research 76: 39-58.

SCHUSSLER RJ \& WESTGATE ME. 1991. Maize kernel set at low potential: I. Sensitivy to reduced assimilates during early kernel growth. Crop Science 31: 1189-1195.

TEDESCO MJ et al. 1995. Análise de solo, plantas e outros materiais. 2.ed. Porto Alegre: UFRGS. 174p.

TONITTO C et al. 2006. Replacing bare fallow with cober crops in fertilizer intensive cropping systems a meta-analsis of crop yield and $\mathrm{N}$ dinamics. Agriculture Ecosystems and Environment 112: 58-72.

ZIECH ARD et al. 2015. Proteção do solo por plantas de cobertura de ciclo hibernal na região Sul do Brasil. Pesquisa Agropecuária Brasileira 50: 374-382. 